\title{
Emotions, Quality of Life and Games in Oncology Outpatient Clinic
}

\author{
Raphaela Espanha Corrêa, Paulo Eduardo Neves Ferreira Velho, Maria Imaculada de Lima Montebello, \\ and Rute Estanislava Tolocka
}

\section{ABSTRACT}

A cancer diagnoses and treatment can trigger unpleasant emotions, which may affect the Quality of Life (QoL). Games are known to promote wellness. The aim of this study was to evaluate emotions and QoL of adult cancer patients in medical care waiting rooms and to identify changes in patient emotions after playing board games. A total of 150 patients were included. Emotions were assessed using emojis and QoL with WHOOLBREF. The mean age was $64.8 \pm 9.6$ years. QoL was measured as 'good' just in the social domain (score $72.38 \pm \mathbf{1 3 . 2 4}$ ). The most frequently reported emotion before playing was joy $(58.0 \%)$, followed by neutral $(21.3 \%)$, sadness $(8.7 \%)$ and fear $(6.7 \%) ; 34.0 \%$ of the patients accepted to play a board game. Emotions of neutrality and sadness in these patients significantly changed to joy after playing the game $(p<0.05)$. We conclude that participation in games might positively change emotions in waiting rooms.

Keywords: Quality of Life, Cancer, Emotions, Emoji, Games.

Published Online: January 22, 2021

ISSN: $2593-8339$

DOI: $10.24018 /$ ejmed.2021.3.1.611

R. E. Corrêa *

Faculty of Medical Sciences - FCM,

University of Campinas - UNICAMP,

Campinas, SP, Brazil.

(e-mail: raphaespanha@yahoo.com.br)

P. E. N. F. Velho

Faculty of Medical Sciences - FCM,

University of Campinas - UNICAMP,

Campinas, SP, Brazil.

(e-mail: pvelho@ unicamp.br)

M. I. L. Montebello

Human Movement Sciences Graduate

Program, Methodist University of

Piracicaba - UNIMEP, Piracicaba, SP, Brazil.

(e-mail: milmonte@gmail.com)

R. E. Tolocka

Human Movement Sciences Graduate Program, Methodist University of Piracicaba - UNIMEP, Piracicaba, SP, Brazil.

(e-mail: nupemlab@gmail.com)

*Corresponding Author

\section{INTRODUCTION}

A cancer diagnosis is a stressful experience that may worsen patient emotions, due to treatments and changes in daily routines [1]-[5], besides that psychosocial factors such as fear and anxiety can influence the perception of cancer risk [6]. Such changes may include hospital visits and time spent in hospital waiting rooms, which can induce emotions that are not positive. A negative emotional state is a natural response that results from the inability to predict, control, and overcome a threatening situation [7]. Thus, this difficult period can produce negative thoughts and reactions. Sadness and fear/anxiety are emotions commonly reported by those patients [8] and may be the most felt emotions in a cancer waiting room [9]. In particular, the negative emotions of fear and sadness may interfere with the course of treatment [10] by affecting immunity or resulting in pain syndromes and somatization [11].

Emotional control during cancer treatment is linked to the process of coping with the disease and includes knowing, exploring, and understanding the emotional experience [12] and the nature of the treatment and its consequences [13].

This work was supported by the The São Paulo Research Foundation, FAPESP [grant number 2017 / 10483-0].
Positive emotions are crucial for adherence to and the success of the treatment regimen and may help with the process of coping with the disease. In the course of emotional regulation, patients with cancer may avoid meeting with other people, decline social invitations [14], or attempt to avoid social activities, all of which may translate to a decrease in their quality of life (QoL) [15].

One method for building social interaction, psychological wellness is to play games as it put people together do make different choices, looking for pleasure [16].

Engaging adult cancer patients in games has played a key role in the coping process, helped them to manage internal conflicts triggered by the disease and it may minimize the pain and suffering experienced of patients during treatment [17]

In addition, these activities such as playing with clowns, and games have been reported to improve the expression of feelings, increase interactions with health teams [18], deal with situations of distress and discomfort and allow for the sensations of relaxation and fun. To take part in games may allow patients to increase their ability to understand and to deal with situations related to diseases, thereby increasing his well-being [19]. However, studies involving games for adult cancer patients remain scarce. 
Basic human feelings such as joy, sadness, anger, fear, surprise, disgust, and neutrality can be recognized in universal facial expressions. Previous studies have validated the assessment of emotions 'in the moment' by encouraging individuals to verbally express them and correlating these with photographs of facial expressions that are characteristic of the emotion [20]. Moreover, these emotions have been observed in people from different countries and customs and are considered universal [21]-[23]. Caricatures of these facial expressions have been created to be used in the electronic communication, the emoticon (sequences of punctuation marks representing facial expressions) and, with the advent of social networks, they have gained the form of emojis (the pictorial representation of the emoticon) which has solidified the relationship between the icon representing the emotion and the emotion itself [24]. This has enabled the expression of emotions in an easy and enjoyable way, eliminating possible difficulties related to the verbal expression of feelings, as well as facilitating the communication of intentions among individuals [25]. Thus, these emojis may aid in the recognition of emotions experienced by patients in hospital waiting rooms.

The aim of this study was to evaluate the QoL scores and emotions of adult cancer patients in medical care waiting rooms and to identify changes in patient emotions after playing board games in this environment.

\section{MATERIALS AND METHODS}

\section{A. Study Design and Sample}

This was a clinical intervention study that included cancer patients willing to partake in board games [26]. The study took place in two hospitals in the city of Piracicaba, Brazil. The hospitals belong to the Regional Network of Health Care and account for $81 \%$ of all hospital care provided in the region [27]. The minimum sample size was estimated using 122 patients based on the following parameters: the estimated number of new adult cancer cases in Piracicaba in $2018(\mathrm{~N}=3788)$, the prevalence of cancer $(p=0.944759)$, a confidence level of $95 \%$, and a maximum sampling error of $4 \%$. The sample size was increased by approximately $20 \%$ due to the potential for sample reduction if volunteers withdrew their consent for participation. A total sample size of 150 participants was calculated. The study inclusion criteria consisted of patients with a clinical history of cancer, those 40 years of age or older [28], and those who agreed to sign the written, informed consent form.

Each participant was approached at the oncology outpatient clinics of the included hospitals while he (she) was waiting to be attended. The approach began with a question to confirm if the patient had come to receive cancer treatment. If the answer was affirmative the researcher showed him (her) a card with the emoji of Joy, Sadness, Fear, Anger, Surprise, Disgust and Neutrality, asking: "How are you feeling now?" The patient pointed the emoji that represented his (her) feeling and the study was explained to him (her). If the patient accepted to take part in the study by giving his (her) writing agreement, the emotion reported was record. Then the researcher asked him questions from a clinical profile and from a questionnaire about QoL. The patient was then invited to participate in a board game, and he (she)could choose among checkers, memory game, tictac-toe, chess, or dominos. If he (she) did not accept the invitation, the interview was finished. If the patient agreed, the researcher played one of the games with the patient, after which he (she) was again introduced to the card with the seven emojis and asked the question: "How are you feeling now?".

\section{B. Measures}

QoL was assessed using the WHOQOL-Bref (World Health Organization Quality of Life, short version) which has been validated for the Portuguese language [29] and contains 26 questions encompassing four distinct domains: physical, psychological, social, and environmental, along with a general QoL assessment [30]. The score achieved with this instrument used the Australian syntax [31]. This instrument is considered an adequate tool for evaluating QoL in cancer patients [32] and allows for the comparison of these patients with other QoL studies [33]-[35]. Emotions were identified in a card with emojis that represent the basic and universal emotions and that have been used among cancer patients to communicate their feelings [36]. Each emoji was subtitle with the correspondent emotion (Fig. 1). A questionnaire was used to obtain the clinical profiles of the patients.

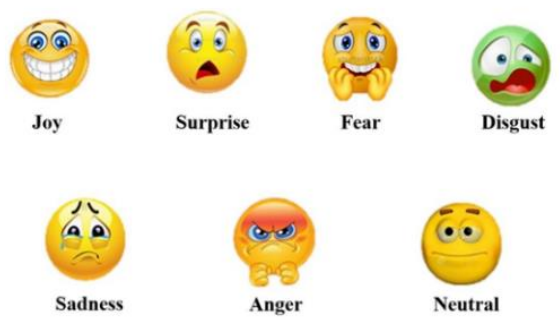

Fig. 1. Emojis (representation of basic emotions).

\section{Ethical Consideration}

This study was conducted in accordance with the tenets of the Helsinki Declaration [37] and received ethical approval from the sponsoring University with protocol number 2.245.786. All participants were informed of the aims and procedures of the study and signed the free and informed consent form.

\section{Data analyses}

The internal consistency of the 26 items that compose the WHOQOL-Bref instrument were confirmed using the Cronbach Alpha reliability test [38]. A descriptive analysis of the variables included in the study was performed. Quantitative variables are expressed as means and standard deviations. Qualitative variables are shown as absolute values and percentages, and the results are presented in contingency tables. To evaluate the influence of games on the emotions a chi-square test was performed. A comparison of the association between the QoL scores and willingness to play a game was analyzed by the non-parametric MannWhitney U test. All tests were two-tailed, and the criterion for statistical significance was $p<0.05$. Statistical analyses were performed using the Statistical Package for Social Sciences (SPSS ver. 20) software (IBM Corp., Armonk, NY, 
United States).

\section{RESULTS}

A total of 150 patients participated in the study. Females comprised $64.0 \%$ of the sample and the mean age was $63.50 \pm 10.49$ years (range: 40.0 to 86.7 years). Breast $(40.7 \%)$ and prostate cancer $(23.3 \%)$ were the most frequent cancer types. A more detailed description of patient clinical profiles is provided in Table I.

The reliability of the QoL data assessed using the Cronbach Alpha test was good, with $a=0.857$ (for all items). Overall, the QoL level was 'low'. The social domain was only one to reach a score of 'good' (72.38 \pm 13.24$)$, Table II.

The emotions most frequently expressed by patients before answering the questionnaires were joy (58.0\%), neutral $(21.3 \%)$ and sadness $(8.7 \%)$. Board game activities were accepted by $34 \%(n=51)$ of the patients. There was no significant association between QoL scores and participation in the games $(p=0.68)$ in any one of QoL domains, Table III. There was no statistically significant association between QoL scores and patient clinical profiles, Table IV.

Chi-square tests between each emotion before and after game, showed that emotions of neutrality and sadness changed significantly after playing board games with $\mathrm{p}=0.003(p<0.05)$, after playing board games $60.0 \%$ reports of sadness, $66.5 \%$ of neutrality and $55.0 \%$ of fear changed into joy; reports of joy increased $33.0 \%$. The Table V shows the distribution of each emotion before and after the game.
TABLE I: CLINICAL PROFILE OF THE STUDY PARTICIPANTS

\begin{tabular}{|c|c|c|c|}
\hline Variable & Categories & $\mathrm{N}$ & $\%$ \\
\hline \multirow{2}{*}{ Age } & $40-59$ & 48 & 32.0 \\
\hline & $\geq 60$ & 102 & 68.0 \\
\hline \multirow{2}{*}{ Sex } & Female & 96 & 64.0 \\
\hline & Male & 54 & 36.0 \\
\hline \multirow{6}{*}{ Cancer Type } & Breast & 61 & 40.7 \\
\hline & Prostate & 35 & 23.3 \\
\hline & Gastrointestinal & 17 & 11.3 \\
\hline & Head and Neck & 6 & 4.0 \\
\hline & Blood & 5 & 3.3 \\
\hline & Other & 26 & 17.3 \\
\hline \multirow{3}{*}{ Phase } & In-Treatment & 49 & 32.7 \\
\hline & Post-Treatment & 101 & 67.3 \\
\hline & Chemotherapy & 25 & 16.7 \\
\hline \multirow[t]{2}{*}{ Treatment } & Radiotherapy & 13 & 8.7 \\
\hline & Other & 11 & 7.3 \\
\hline \multirow{2}{*}{ Surgery } & Yes & 117 & 78.0 \\
\hline & No & 33 & 22.0 \\
\hline \multirow{7}{*}{ Emotions } & Joy & 87 & 58.0 \\
\hline & Sadness & 13 & 8.7 \\
\hline & Fear & 10 & 6.7 \\
\hline & Anger & 1 & 0.7 \\
\hline & Surprise & 5 & 3.3 \\
\hline & Disgust & 2 & 1.3 \\
\hline & Neutrality & 32 & 21.3 \\
\hline
\end{tabular}

TABLE II: AVERAGE QUALITY OF LIFE DOMAIN SCORES OF THE STUDY PARTICIPANTS

\begin{tabular}{cccc}
\hline Domains & Minimum & Maximum & Mean \pm SD \\
\hline Physical & 21.43 & 92.86 & $59.07 \pm 11.25$ \\
Psychological & 12.50 & 83.33 & $61.74 \pm 13.74$ \\
Environmental & 25.00 & 93.75 & $64.29 \pm 13.28$ \\
Social & 25.00 & 100.00 & $72.38 \pm 13.24$ \\
\hline
\end{tabular}

TABLE III: QUALITY OF LIFE DOMAINS AND WILLINGNESS TO PLAY

\begin{tabular}{cccc}
\multicolumn{4}{c}{ BOARD GAMES } \\
\hline Domains & Players & No players & $\mathrm{U}$ \\
\hline PhyD & $59.80 \pm 12.69$ & $58.69 \pm 10.48$ & -0.73 \\
PsyD & $62.33 \pm 14.26$ & $61.44 \pm 13.53$ & -0.66 \\
SD & $73.85 \pm 13.43$ & $71.63 \pm 13.14$ & -1.38 \\
ED & $65.68 \pm 13.51$ & $63.57 \pm 13.18$ & -1.25 \\
\hline
\end{tabular}

Legend. U= Mann-Whitney test; QoL= Quality of Life; Domains: PhyD= Physical; PsyD= Psychological; $\mathrm{SD}=$ Social; $\mathrm{ED}=$ Environment; Values represent in (mean $\pm \mathrm{SD})$.

TABLE IV: QUALITY OF LIFE SCORES AND PATIENT CLINICAL PROFILES

\begin{tabular}{|c|c|c|c|c|c|c|c|c|c|}
\hline \multirow{3}{*}{ Variables } & \multirow{3}{*}{ Categories } & \multicolumn{8}{|c|}{$\mathrm{n}(\%)$} \\
\hline & & \multicolumn{2}{|c|}{ QoL Physical } & \multicolumn{2}{|c|}{ QoL Psychological } & \multicolumn{2}{|c|}{ QoL Social } & \multicolumn{2}{|c|}{ QoL Environmental } \\
\hline & & Poor & Adequate & Poor & Adequate & Poor & Adequate & Poor & Adequate \\
\hline \multirow[t]{2}{*}{ Age } & $40-59$ & $46(30.7)$ & $2(1.3)$ & $29(19.3)$ & $19(12.7)$ & $16(10.7)$ & $32(21.3)$ & $36(24.0)$ & $12(8.0)$ \\
\hline & $\geq 60$ & $85(56.7)$ & $17(11.3)$ & $68(45.3)$ & $34(22.7)$ & $44(29.3)$ & $58(38.7)$ & $67(44.7)$ & $35(23.3)$ \\
\hline \multirow[t]{2}{*}{ Sex } & Female & $85(56.7)$ & $11(7.3)$ & $66(44.0)$ & $30(20.0)$ & $40(26.7)$ & $56(37.3)$ & $67(44.7)$ & $29(19.3)$ \\
\hline & Male & $46(30.7)$ & $8(5.3)$ & $31(20.7)$ & $23(15.3)$ & $20(13.3)$ & $34(22.7)$ & $36(24.0)$ & $18(12.0)$ \\
\hline \multirow[t]{6}{*}{ Cancer } & Breast & $51(34.0)$ & $10(6.7)$ & $41(27.3)$ & $30(13.3)$ & $24(16.0)$ & $37(24.7)$ & $42(28.0)$ & $19(12.7)$ \\
\hline & Prostate & $31(20.7)$ & $4(2.7)$ & $22(14.7)$ & $13(6.7)$ & $14(9.3)$ & $21(14.0)$ & $24(16.0)$ & $11(7.3)$ \\
\hline & Gastrointestinal & $15(10.0)$ & $2(1.3)$ & $12(8.0)$ & $5(3.3)$ & $8(5.3)$ & $9(6.0)$ & $14(9.3)$ & $3(2.0)$ \\
\hline & Head and Neck & $6(4.0)$ & $0(0.0)$ & $3(2.0)$ & $3(2.0)$ & $3(2.0)$ & $3(2.0)$ & $3(2.0)$ & $3(2.0)$ \\
\hline & Blood & $5(3.3)$ & $0(0.0)$ & $3(2.0)$ & $2(1.3)$ & $1(0.7)$ & $4(2.7)$ & $4(2.7)$ & $1(0.7)$ \\
\hline & Other & $23(15.3)$ & $3(2.0)$ & $16(10.7)$ & $10(6.7)$ & $10(6.7)$ & $16(10.7)$ & $16(10.7)$ & $10(6.7)$ \\
\hline \multirow[t]{2}{*}{ Phase } & In-Treatment & $44(29.3)$ & $5(3.3)$ & $37(24.7)$ & $12(8.0)$ & $22(14.7)$ & $27(18.0)$ & $34(22.7)$ & $15(10.0)$ \\
\hline & Post-Treatment & $87(58.0)$ & $14(9.3)$ & $60(40.0)$ & $41(27.3)$ & $38(25.3)$ & $63(42.0)$ & $69(46.0)$ & $32(21.3)$ \\
\hline \multirow{3}{*}{ Treatment } & Chemotherapy & $22(44.9)$ & $3(6.1)$ & $14(28.6)$ & $11(22.4)$ & $6(12.2)$ & $19(38.8)$ & $18(36.7)$ & $7(14.3)$ \\
\hline & Radiotherapy & $12(24.5)$ & $1(2.0)$ & $7(14.3)$ & $6(12.2)$ & $7(14.3)$ & $6(12.2)$ & $11(22.4)$ & $2(4.1)$ \\
\hline & Other & $9(18.4)$ & $2(4.1)$ & $9(18.4)$ & $2(4.1)$ & $6(12.2)$ & $5(10.2)$ & $9(18.4)$ & $2(4.1)$ \\
\hline \multirow{5}{*}{ Surgery } & Yes & $99(66.0)$ & $18(12.0)$ & $76(50.7)$ & $41(27.3)$ & $50(33.3)$ & $67(44.7)$ & $78(52.0)$ & $39(26.0)$ \\
\hline & No & $32(21.3)$ & $1(0.7)$ & $21(14.0)$ & $12(8.0)$ & $10(6.7)$ & $23(15.3)$ & $25(16.7)$ & $8(5.3)$ \\
\hline & Joy & $73(48.7)$ & $14(9.3)$ & $48(32.0)$ & $39(26.0)$ & $34(22.7)$ & $53(35.3)$ & $54(36.0)$ & $33(22.0)$ \\
\hline & Sadness & $12(8.0)$ & $1(0.7)$ & $9(6.0)$ & $4(2.7)$ & $4(2.7)$ & $9(6.0)$ & $10(6.7)$ & $3(2.0)$ \\
\hline & Fear & $10(6.7)$ & $0(0.0)$ & $10(6.7)$ & $0(0.0)$ & $4(2.7)$ & $6(4.0)$ & $10(6.7)$ & $0(0.0)$ \\
\hline \multirow[t]{4}{*}{ Emotions } & Anger & $1(0.7)$ & $0(0.0)$ & $1(0.7)$ & $0(0.0)$ & $1(0.7)$ & $0(0.0)$ & $1(0.7)$ & $0(0.0)$ \\
\hline & Surprise & $4(2.7)$ & $1(0.7)$ & $3(2.0)$ & $2(1.3)$ & $2(1.3)$ & $3(2.0)$ & $3(2.0)$ & $2(1.3)$ \\
\hline & Disgust & $2(1.3)$ & $0(0.0)$ & $2(1.3)$ & $0(0.0)$ & $0(0.0)$ & $2(1.3)$ & $2(1.3)$ & $0(0.0)$ \\
\hline & Neutral & $29(19.3)$ & $3(2.0)$ & $24(16.0)$ & $8(5.3)$ & $15(10.0)$ & $17(11.3)$ & $23(15.3)$ & $9(6.0)$ \\
\hline
\end{tabular}


TABLE V: EMOTIONS BEFORE AND AFTER TAKING PART IN A GAME

\begin{tabular}{|c|c|c|c|c|c|c|c|c|}
\hline & & & \multicolumn{5}{|c|}{ Emotions after playing games } & \multirow[b]{2}{*}{ Total } \\
\hline & & & Joy & Sadness & Fear & Surprise & Neutral & \\
\hline \multirow{9}{*}{$\begin{array}{l}\text { Emotions } \\
\text { before playing } \\
\text { games }\end{array}$} & Joy & $\begin{array}{c}\text { Count } \\
\%\end{array}$ & $\begin{array}{c}32_{\mathrm{a}} \\
97.0 \%\end{array}$ & $\begin{array}{c}0_{\mathrm{a}} \\
0.0 \%\end{array}$ & $\begin{array}{c}0_{\mathrm{a}} \\
0.0 \%\end{array}$ & $\begin{array}{c}1_{\mathrm{a}} \\
3.0 \%\end{array}$ & $\begin{array}{c}0_{\mathrm{a}} \\
0.0 \%\end{array}$ & $\begin{array}{c}33 \\
100.0 \%\end{array}$ \\
\hline & Sadness & $\begin{array}{c}\text { Count } \\
\%\end{array}$ & $\begin{array}{c}3 \mathrm{a} \\
60.0 \%\end{array}$ & $\begin{array}{c}1_{b} \\
20.0 \%\end{array}$ & $\begin{array}{c}0_{\mathrm{a}, \mathrm{b}} \\
0.0 \%\end{array}$ & $20 \frac{1}{\mathrm{a}, \mathrm{b}}$ & $\begin{array}{c}0_{\mathrm{a}, \mathrm{b}} \\
0.0 \%\end{array}$ & 5 \\
\hline & & Count & $1_{\mathrm{a}}$ & $0_{\mathrm{a}, \mathrm{b}}$ & $1_{\mathrm{b}}$ & $0_{\mathrm{a}, \mathrm{b}}$ & $0_{a, b}$ & 2 \\
\hline & Fear & $\%$ & $50.0 \%$ & $0.0 \%$ & $50.0 \%$ & $0 . \overline{0 \%}$ & $0.0 \%$ & $100.0 \%$ \\
\hline & Surprise & $\begin{array}{c}\text { Count } \\
\%\end{array}$ & $\begin{array}{c}1_{\mathrm{a}} \\
100.0 \%\end{array}$ & $\begin{array}{c}0_{\mathrm{a}} \\
0.0 \%\end{array}$ & $\begin{array}{c}0_{\mathrm{a}} \\
0.0 \%\end{array}$ & $\begin{array}{c}0_{\mathrm{a}} \\
0.0 \%\end{array}$ & $\begin{array}{c}0_{\mathrm{a}} \\
0.0 \%\end{array}$ & $\begin{array}{c}1 \\
100.0 \%\end{array}$ \\
\hline & & Count & $1_{\mathrm{a}}$ & $0_{\mathrm{a}}$ & $0_{\mathrm{a}}$ & $0_{\mathrm{a}}$ & $0_{\mathrm{a}}$ & 1 \\
\hline & Disgust & $\%$ & $100.0 \%$ & $0.0 \%$ & $0.0 \%$ & $0.0 \%$ & $0.0 \%$ & $100.0 \%$ \\
\hline & Neutral & Count & 6 a & $0_{\underline{a, b}}$ & $0_{\underline{a, b}}$ & $1_{\underline{\mathrm{a}, \mathrm{b}}}$ & $2 \mathrm{~b}$ & 9 \\
\hline & Nentrá & $\%$ & $66.7 \%$ & $0.0 \%$ & $0 . \overline{0 \%}$ & $11.1 \%$ & $22.2 \%$ & $100.0 \%$ \\
\hline \multirow{2}{*}{ Total } & & Count & 44 & 1 & 1 & 3 & 2 & 51 \\
\hline & & $\%$ & $86.3 \%$ & $2.0 \%$ & $2.0 \%$ & $5.9 \%$ & $3.9 \%$ & $100.0 \%$ \\
\hline
\end{tabular}

Letters "a" and "b" show the results of comparing the proportions of each line (category); different letters together indicate significant differences within the analyzed category.

\section{DISCUSSION}

The present study is one of the first to evaluate QoL and the emotions of adult cancer patients before and after playing board games in the waiting rooms of outpatient clinics. QoL measurement tools involve a number of domains such as physical, social, sexual, spiritual, cognitive and psychological [39]. In the present study, the patients showed high QoL scores only in relation to the social domain, with a mean score of $72.38 \pm 13.24$. The lowest mean score was in the physical domain at $59.07 \pm 11.25$ points. These findings are in agreement with previous studies [33], [40] investigating patients diagnosed with breast cancer that also found higher scores in the social domain and lower scores in the physical one. Social support, primarily consisting of care from family and friends during the disease and treatment process, can play a fundamental role in the lives of patients. Rukshani et al. [41] reported that patients who felt alone had low QoL scores, while those who stated they had strong family support had higher scores.

The physical domain of the QoL is composed of 7 facets that include issues related to pain, medical treatment, physical appearance, sleep, and satisfaction with physical ability. Although we found no significant associations between the phases or types of treatments and patient QoL scores, the often-invasive treatments that patients undergo can result in transient, undesirable side effects such as headaches, fatigue, and weakness [42]. These symptoms may then significantly affect their QoL scores [43], which may be one of the reasons why patients presented low scores in this domain. Patients with more comorbidities also typically have low QoL scores in the physical domain [44].

Individual perceptions, concerns and expectations, along with diseases that affect the lives of patients, can directly affect QoL scores [45], [46]. However, even in stressful environments such as the waiting rooms of outpatient clinics, more than half of the patients in this study indicated experiencing positive emotions. This may be related to feelings of being cared for in these environments; and, leading to feeling more secure in their treatment. This is important, as positive emotions may act as mediators when patients encounter negative and stressful situations [47]. Consequently, patients may generate new, positive emotions. This cycle can contribute to the well-being of the individual and generate an increase in positive emotions during future experiences [48]. Although many of the patients in the present study reported a positive emotional state (joy), we also found, to a lesser degree, states of neutrality $(21.3 \%)$ sadness $(8.7 \%)$, and fear $(6.7 \%)$. These findings differ from those of Resega et al. [10], in which cancer patients who waited for procedures in waiting rooms exhibited more sadness and fear. No significant associations were found between the QoL from different domains and the emotions the patients reported, but evidence has shown that emotional problems may be related to poor QoL scores in patients with Lung cancer [49].

In this study, the strategy of implementing activities in the waiting room was achieved through playfulness, specifically through use of various board games, which were played by 51 patients $(34 \%)$. There was association between the treatment phase and the acceptance to play game (X2 $\mathrm{p}=0.038$ for $\mathrm{p}<0.05)$ and the adherence to play games was greater among the patients who were in the post-treatment phase.

No significant associations were found between the QoL domains and the type of game played, and the QoL scores did not affect the probability of engaging in a game. Hence, games may be played regardless of the patients' QoL levels. This may be due to the fact that these patients exhibit minor side effects at the end of treatment, resulting in a greater willingness to engage in different activities. However, games were also accepted by patients during the treatment phase $(7.3 \%)$, demonstrating that game acceptance included patients with varying clinical profiles.

Ressega et al. [10] reported that approximately $35 \%$ of clinical patients showed an interest in activities that contributed to their distraction while waiting for procedures. This percentage is very similar to the rate of game acceptance in the present study. While some patients showed more interest in engaging in different activities in these environments, more studies are necessary to better understand the reasons why a patient accepts an invitation to engage in game play.

The creation of different experiences in hospital waiting rooms by means of recreational activities may contribute to a significant decrease in patient anxiety, as well as allow patients to better confront their circumstances and change how they perceive their time spent in hospital settings [50]. In addition, the implementation of activities that promote patient enjoyment during the time spent in waiting rooms 
has been seen by the patients themselves as a way to minimize the emotional suffering experienced in these settings [51].

In this study, the majority of patients $(64.7 \%)$ who played games indicated their initial emotion as joy. This may indicate that patients with positive affective states are more likely to engage in diverse activities that contribute to their abilities to cope with adverse situations. Although scarce, there is some evidence suggesting that patients who play games in waiting rooms experience positive emotions in regard to their general well-being [52]. Affective states can be contextualized as a term that encompasses responses to stress, mood, and emotions, where the regulation of these components also involves adopting coping strategies under certain circumstances [53]. As emotions are considered acute affective states triggered by specific stimuli and contexts [14], we observed that games acted as a stimulus capable of generating positive emotions in specific contexts, inclusive of outpatient-clinic waiting rooms.

There is growing evidence of the benefits of playful activities, including improvements in coping mechanisms, emotional states, well-being [18], managing internal conflicts [17], the expression of feelings other than the lessening of negative thoughts [19], and an increase in positive emotions that occur in waiting rooms [54].

Games are characterized as an activity that is spontaneous and without material interest [55]. Playful activities in children under medical treatment allow for the externalization of possible conflicts such as fear, uncertainty and anguish, and are known to improve well-being [56], [57]. These same outcomes may also occur with emotionally stressed, adult cancer patients. The challenge is to transform outpatient settings into spaces that naturally allow for the expression of the feelings and desires of these patients. Furthermore, game playing may contribute to an increase in the interactions between adult patients, their families and the outpatient clinic staff, as occurs with pediatric cancer patients and their families [58].

\section{LIMITATIONS}

We offered only one opportunity for patients to play games with the researcher. More opportunities to engage in play may produce additional results that lead to a better understanding of playful activities in these environments.

\section{CONCLUSIONS}

Adult cancer patients showed low QoL scores in the physical, psychological, and environmental domains, with high scores occurring only in the social domain, demonstrating how affected the overall QoL of cancer patients can be.

Joy was the feeling most commonly expressed by participants at the outpatient clinics, although fear, sadness, and anger were also reported. Thus, it is observed that different emotions can be manifested in outpatient waiting rooms, nevertheless, the reasons for such are not yet clear.
However, patients with negative emotions who participated in the games demonstrated a change towards positive emotions, indicating the beneficial role that games can have in the short term in hospital environments such as the waiting room.

We did detect a tendency for games to be accepted by patients, especially those with positive-affective states. It is noted that there is possibly a tendency for patients with positive emotional states to present greater engagement in relation to the activities implemented in hospitals. Patients in the post-treatment phase exhibited a greater willingness to accept game play.

The present work provides data about QoL and the basic emotions manifested by cancer patients, as well as about the role of games in the health context.

The study showed that adult patients with cancer history may benefit from games while waiting for an appointment, contributing to the minimization of negative emotions.

Further studies are needed to understand why patients experience particular emotions in medical care waiting rooms and to assess the collective role of games in hospital settings.

\section{ACKNOWLEDGMENT}

The authors thank all patients, hospitals, oncology centers, and reviewers who contributed to the study.

\section{REFERENCES}

[1] A.C. All and L.I. Huycke. "Pain, Cancer, and Older Adults (CE)," Geriatric Nursing, vol.20, n.5, pp. 241-247, 1999.

[2] T.F.H. Deitos and J.F.P. Gaspary. "Cancer biopsychosocial and psychoneuroimmunologic effects on patients and their families," Rev Bras Cancerol, vol.43, n.2, pp. 117-126, 1997.

[3] T. Juvakka and J. Kylmã. "Hope in adolescents with cancer," Eur J OncolNurs, vol.13, n.3, pp.193-199, 2009

[4] S.E. Mac Lement and H.M. Chochinov. "Hope in advanced cancer patients," Eur J Cancer, vol. 44, n.8, pp.1169-1174, 2008.

[5] A.M. Reb. "Transforming the death sentence: elements of hope in women with advanced ovarian cancer," OncolNurs Forum, vol. 34, n.6, pp. 70-81, 2007.

[6] R.Y. Wood and N.R. Della-Monica. "Psychosocial Factors Influencing Breast Cancer Risk Appraisal Among Older Women,' Qualitative Health Research, vol. 783-795, 2011.

[7] W. Chen, R. Zheng, P.D. Baade, S. Zhang, H. Zeng, F. Bray, A. Jemal, X.Q. Yu and J. He. "Cancer statistics in China," CA Cancer J Clin, vol.66, n.2, pp.115-132, 2016

[8] S.K. Park, H.A. Park and J. Lee. "Understanding the Public's Emotions about Cancer: Analysis of Social Media Data," Int J Environ Res Public Health, vol.17, n.19, pp. E7160, 2020.

[9] S.S. Silva, T.A.A. Aquino and R.M. Santos. "Patients with cancer: cognitions and emotions coming from diagnosis," Rev bras tercogn, vol. 4, n.2, pp. 73-88, 2008 .

[10] R. Resega, S. Piva, A. Bramati, C. Lurati, N. La Verde, M. Riva, M.C. Garassino, A. Moretti, C. Mencacci, V. Torri, G. Farina, M.C Dazzani. "Prospective evaluation through questionnaires of the emotional status of cancer patients in the waiting rooms of a department of oncology," J Health SocSci, vol.1, n.2, pp.113-122, 2016.

[11] J. Barraclough, Cancer and emotion - A practical guide to psychooncology, Chichester: John Wiley, 1999.

[12] S.E. Hullman, S.L. Robb and K.L. "Rand. Life goals in patients with cancer: a systematic review of the literature," Psychooncology, vol.25, n.4, pp. 387-399, 2016.

[13] G.J. Yoo, E.G. Levine, C. Aviv, C. Ewing and A. Au. "Older women, breast cancer, and social support," SupportCareCancer, vol. 18, n.12, pp.1521-1530, 2010. 
[14] M. Kangas and J.J. Gross. "The affect regulation in cancer framework: Understanding affective responding across the cancer trajectory," J Health Psychol, vol.25, n.1, pp.1-19, 2017.

[15] G.I. Ringdal, K. Ringdal, M.S. Jordhoy and S. Kaasa. "Does social support from family and friends work as a buffer against reactions to stressful life events such as terminal cancer?," Palliat Supportive, vol. 5, n. 1, pp. 61-69, 2007.

[16] L.J. Haywood, F.C. Kew, P. Bramham, J. Spink, J. Capenerhurst and I. Henry. Understanding Leisure; New York: Stanley Thornes, 2019.

[17] R.C. Giuliano, L.M.S. Silva and N.M. Orozimbo. "Reflection on "playing" in the therapeutical work with adult patients with cancer," PsicolCiencProf, vol.29, n.4, pp.868-879, 2009.

[18] C.C. Moura, Z.M.R. Resck and E.M.R. Dázio. "Recreational activities performed with neoplasia carrier inpatients in a general hospital," Rev Rene, vol.13, n.3, pp. 667-676, 2012.

[19] A.K. Pon. "My wonderful life: A board game for patients with advanced cancer," ILLNESS, CRISIS \& LOSS, vol.18, n.2, pp. 147 161, 2010.

[20] P. Ekman, Basic emotions in: Handbook of Cognition and Emotion, Sussex: Wiley \& Sons, 2005.

[21] M.G. Beaupré and U. Hess. "Cross-cultural emotion recognition among Canadian ethnic groups," J Cross Cult Psychol, vol. 36, n.1, pp.355-370, 2005.

[22] A. Schirmer and R. Adolphs. "Emotion perception from face, voice, and touch: Comparisons and convergence," Trends CognSci, vol.21, n.3, pp. 216-228, 2017.

[23] K.L. Schmidt and J. Cohn. "Human facial expressions as adaptations: Evolutionary questions in facial expression," Am J PhysAnthropol, vol.44, n.1, pp.3-24, 2001

[24] A. Sampietro. "Emoji and rapport management in Spanish WhatsApp chats," Journal of Pragmatics, vol. 143, pp.109-120, 2019.

[25] J.C. Reis, C. Jensen, R. Bonacin, H. Hornung and C.C. Baranauskas. "Expressive icons for the communication of intentions," ICEIS, vol.2, n.1, pp. 388-399, 2016

[26] B. Röhrig, J.B. Prel, D. Wachtlin and M. Blettner. "Types of Study in Medical Research: Part 3 of a Series on Evaluation of Scientific Publications," DtschArztebl Int, vol.106, n.15, pp. 262-268, 2009.

[27] Fundação Oncocentro de São Paulo (March 2014). Caracterização da assistência oncológica nas Redes Regionais de Atenção à Saúde no estado de São Paulo (Characterization of câncer care in the Regional Health Care Networks in the state of São Paulo-Br), Rede Hebe Camargo de Combate ao câncer [online].

[28] D.E. Papalia and G. Martorell, Experience Human Development New York: McGraw-Hill Education, 2014

[29] M.P.A. Fleck, S. Louzada, M. Xavier, E. Chachamovich, G. Vieira, L. Santos and V. Pinzon. "Application of the Portuguese version of the abbreviated instrumentof quality of life WHOQOL-bref," Rev. SaúdePública, vol.34, n.2, pp.178-183, 2000 doi.org/10.1590/S0034-89102000000200012.

[30] The WHOQOL Group. "Development of the World Health Organization WHOQOL-BREF Quality of Life Assesment," Psycho Med, vol.28, n.5, pp.551-558, 1998

[31] The Australian Centre for Postraumatic Mental Health. Trauma related research, training and policy development [online]. Available:

http://www.psychiatry.unimelb.edu.au/qol/whoqol/whoqolinsrument s.html\#algorithm.

[32] M. Tazaki, Y. Nakane, T. Endo, F. Kakikawa, K. Kano, H. Kawano, K. Kuriyama, K. Kuroko, E. Miyaoka, H. Ohta, N. Okamoto, S Shiratori, S. Takamiya, K. Tanemura and R. Tsuchiya. "Results of a qualitative and field study using the WHOQOL instrument for cancer patients," Jpn J ClinOncoI, vol.28, n.2, pp.134-141, 1998 http://doi.org/10.1093/jjco/28.2.134.

[33] V.A. Ferreira, I.N.T. Silveira, N.S. Gomes, M.T. Ruiz and S.R Silva. "Quality of life of women with gynecologic and breast cancer undergoing chemotherapy," Rev Rene, vol.16, n.2, pp.266-274, 2015.

[34] T.C. Mansano-Schlosser and M.F. Ceolim. "Quality of life of cancer patients during thechemotherapy period," Texto\&contextoenferm, vol. 21, n.3, pp.600-607, 2012.

[35] A. Pacian, T.B. Kulik, J. Pacian, P. Chruściel, D. ŻołnierczukKieliszek and M.J. Jarosz. "Psychosocial aspect of quality of life of Polish women with breast cancer," Ann Agric Environ Med, vol.19, n.3, pp. 509-512, 2012.

[36] M. Huesch, A. Chetlen, J. Segel and S. Schetter. "Frequencies of Private Mentions and Sharing of Mammography and Breast Cance
Terms on Facebook: A Pilot Study," J Med Internet Res, vol.19, n.6, pp. 201, 2017.

[37] World Medical Association. (November 2013) WMA. Declaration of Helsinki -Ethical Principles for Medical Research Involving Human Subjects. [online]. Available: https://www.wma.net/wpcontent/uploads/2016/11/DoH-Oct2013-JAMA.pdf

[38] L.J. Cronbach. "Coefficient alpha and the internal structure of test," Psychometrika, vol.16, n.3, pp.297-334, 1983

[39] D. Osoba. "Lessons Learned from Measuring Health-Related Quality of Life in Oncology," J ClinOncol, vol.12, n.3, pp.608-616, 1994.

[40] E.A. Araújo Neto, B. Alves, F.S. Gehrke, L.A. Azzalis, V.C.B. Junqueira, L.V.A. Sousa and F. Adami, F.L.A. Fonseca. "Quality of Life of Post-Mastectomy Women Living in a Semi-Arid Region of Brazil," Int J Environ Res Public Health, vol.16, n.6, pp.601, 2017.

[41] D. Rukshani, P. Kahandawala, K. Jayawardana, D. Karunarathne, L.S. Galgamuwa, C. Kumara, C. Gamage. "Factors associated with quality of life among cancer patients in Sri Lanka," IJCMPH, vol.5, n.7, pp.2705-2713, 2018

[42] M.S. Aslam, S. Naveed, A. Ahmed, Z. Abbas and M.A.A. Gull. "Side Effects of Chemotherapy in Cancer Patients and Evaluation of Patients Opinion about Starvation Based Differential Chemotherapy," J CancerTher, vol.5, n.8, pp.817-822, 2014.

[43] M.P.A. Fleck, Avaliação da qualidade de vida: Guia para profissionais da saúde - Qualityof Life evaluation: a guide for health professional, Porto Alegre: ArtMed, 2008.

[44] J.L. Rodriguez, N.A. Hawkins, Z. Berkowitz and C. Li. "Factors Associated with Health-Related Quality of Life Among Colorectal Cancer Survivors," AJPM, vol.5, pp.518-527, 2015.

[45] The Whoqol Group, The development of the World Health Organization quality of life assessment instrument (the WHOQOL) in Orley J, Kuyken W, editors. Quality of life assessment: international perspectives, Heidelberg: Springer Verlag, pp. 41-6, 1994.

[46] B.P. Hermann. "The evolution of health-related quality of life assessement in epilepsy," Qual life Res, vol.4, n.2, pp.87-100, 1995.

[47] M.M. Tugade and B.L. Fredrickson. "Resilient Individuals Use Positive Emotions to Become back from Negative Emotional Experiences," J PersSocPsychol, vol.86, n.2, pp.320-333, 2004.

[48] B.L. Fredrickson and T. Joiner. "Positive Emotions Trigger Upward Spirals Toward Emotional Well-Being," Psychological Science, vol.13, n.2, pp.172-175, 2002

[49] E.J. Morrison, P.J. Novotny, J.A. Sloan, P. Yang, C.A. Patten, K.J. Ruddy and M.M. Clark. "Emotional Problems, Quality of Life, and Symptom Burden in Patients With Lung Cancer," Clin Lung Cancer, vol.18, n.5, pp.97-503, 2017.

[50] E. Aitini, A. Sempreboni, P. Aleotti, D. Zamagni, G. Cavazzini, R. Barbieri, R. Cengarle, C. Rabbi, F. Pari and B. Vivorio. "Anxiety Levels in Cancer Patients and "Life Sound" Experience," Tumori, vol.93, pp.75-77, 2007.

[51] C. Catania, T. De Pas, I. Minchella, F. De Braud, D. Micheli, L. Adamoli, G. Spitaleri, C. Noberasco, A. Milani, M.G. Zampino, F. Toffalorio, D. Radice, A. Goldhirsch, F. Nolè."Waiting and the waiting room: how do you experience them?" emotional implications and suggestions from patients with cancer," J Cancer Educ, vol. 26 n.2, pp.388-94, 2011.

[52] J. Ahloy-Dellaire, J. Espinosa and G. Mason. "Play and optimal welfare: does play behavior indicate the presence of positive affective states?," Behav Processes, vol.156, pp.3-15, 2018.

[53] J.J. Gross. "Emotion regulation: Current status and future prospects,' PsychologicalInquiry, vol.26, pp.1-26, 2015.

[54] L.C.G. Leme, R.E. Corrêa, R.F. Magalhães, P.E.N.F. Velho, R.E. Tolocka. "Play Games in the Waiting Room of Cancer Units: A Preliminary Study," Movement, pp. 220-221, 2018.

[55] J. Huizinga, Homo Ludens, a study of the play element in culture, Boston:Angelico Press, 2016

[56] K. Koukourikos, L. Tzeha, P. Pantelidou, A. Tsaloglidou. "The importance of play during hospitalization of children," Mater Sociomed, vol. 27, n.6, pp. 438-441, 2015.

[57] J.R. Webb. "Play Therapy with hospitalized children," International Journal of Play Therapy, vol.4, n.1, pp.51-59, 1995.

[58] A.L.C. Costa Junior, S.M.G. Coutinho, R.S. Ferreira. "Planned recreation in pediatric unit waiting room: behavioral effects," Paidéia, vol.16, n.33, pp.111-118, 2006. 